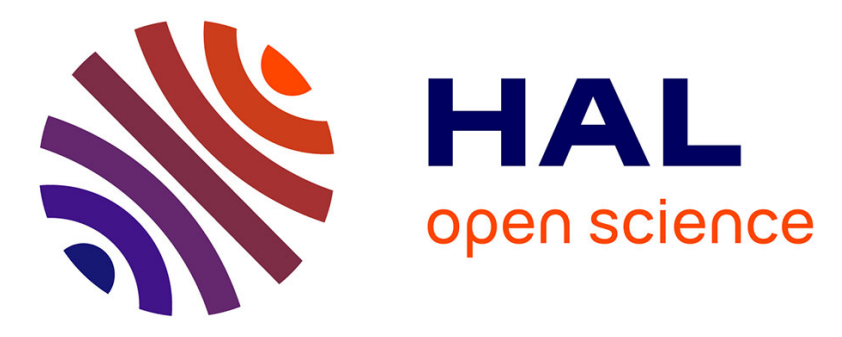

\title{
Liver antioxidant and plasmatic immune responses in juvenile golden grey mullet (Liza aurata) exposed to dispersed crude oil
}

Thomas Milinkovitch, Awa Ndiaye, Wilfried Sanchez, Stéphane Le Floch, Hélène Thomas-Guyon

\section{To cite this version:}

Thomas Milinkovitch, Awa Ndiaye, Wilfried Sanchez, Stéphane Le Floch, Hélène Thomas-Guyon. Liver antioxidant and plasmatic immune responses in juvenile golden grey mullet (Liza aurata) exposed to dispersed crude oil. Aquatic Toxicology, 2011, 101 (1), pp.155-164. 10.1016/j.aquatox.2010.09.013 . hal-00647228

\section{HAL Id: hal-00647228 \\ https://hal.science/hal-00647228}

Submitted on 1 Dec 2011

HAL is a multi-disciplinary open access archive for the deposit and dissemination of scientific research documents, whether they are published or not. The documents may come from teaching and research institutions in France or abroad, or from public or private research centers.
L'archive ouverte pluridisciplinaire HAL, est destinée au dépôt et à la diffusion de documents scientifiques de niveau recherche, publiés ou non, émanant des établissements d'enseignement et de recherche français ou étrangers, des laboratoires publics ou privés. 


\title{
Liver antioxidant and plasmatic immune responses in juvenile golden grey mullet (Liza aurata) exposed to dispersed crude oil
}

\author{
Thomas Milinkovitch $^{1 *}$, Awa Ndiaye ${ }^{2}$, Wilfried Sanchez ${ }^{2}$, Stéphane Le Floch ${ }^{3}$, Hélène
} Thomas-Guyon $^{1 *}$

\section{Affiliations}

${ }^{1}$ Littoral Environnement et Sociétés (LIENSs), UMR 6250, CNRS-Université de La Rochelle, 2 rue Olympe de Gouges - F-17042 La Rochelle Cedex 01, France. Email:

thomas.milinkovitch01@univ-lr.fr ; helene.thomas@univ-lr.fr

${ }^{2}$ Institut National de l'Environnement Industriel et des Risques (INERIS), Unité d'écotoxicologie in vitro et in vivo, Parc Technologique ALATA - F-60550 Verneuil en Halatte, France. Email: Awa.Ndiaye@ineris.fr ; Wilfried.Sanchez@ineris.fr ;

${ }^{3}$ Centre de Documentation de Recherche et d'Expérimentations sur les Pollutions Accidentelles des Eaux (CEDRE), 715 rue Alain Colas, CS41836-F-29218 Brest Cedex 2, France. Email: stephane.le.floch@ cedre.fr

* Corresponding authors: T. Milinkovitch; H. Thomas-Guyon Littoral Environnement et Sociétés (LIENSs) UMR 6250, CNRS-Université de La Rochelle 2 rue Olympe de Gouges F-17042 La Rochelle Cedex 01, France Email : thomas.milinkovitch01@univ-lr.fr helene.thomas@univ-lr.fr tel : $+33(0) 546507648$ fax : +33(0)546458264

\footnotetext{
Abbreviations: BAL : Brut Arabian Light ; C : Control ; CD : Chemically Dispersed oil ; D : Dispersant solution ; MD : Mechanically Dispersed oil; WSF : Water Soluble Fraction
} 
Abstract

Dispersant application is an oil spill response technique. To evaluate the environmental cost of this operation in nearshore habitats, the experimental approach conducted in this study exposed juvenile golden grey mullets (Liza aurata) for 48 hours to chemically dispersed oil (simulating, in vivo, dispersant application), to dispersant alone in sea water (as an internal control of chemically dispersed oil), to mechanically dispersed oil (simulating, in vivo, natural dispersion), to the water-soluble fraction of oil (simulating, in vivo, an oil slick confinement response technique) and to sea water alone (control condition). Biomarkers such as fluorescence of biliary polycyclic aromatic hydrocarbon (PAH) metabolites, total glutathione liver content, EROD (7-ethoxy-resorufin-Odeethylase) activity, liver antioxidant enzyme activity, liver lipid peroxidation and an innate immune parameter (haemolytic activity of the alternative complement pathway) were measured to assess the toxicity of dispersant application. Significant responses of PAH metabolites and total glutathione liver content to chemically dispersed oil were found, when compared to water-soluble fraction of oil. As it was suggested in other studies, these results highlight that priority must be given to oil slick confinement instead of dispersant application. However, since the same patterns of biomarkers responses were observed for both chemically and mechanically dispersed oil, the results also suggest that dispersant application is no more toxic than the natural dispersion occurring in nearshore areas (e.g. waves). The results of this study must, nevertheless, be interpreted cautiously since other components of nearshore habitats must be considered to establish a framework for dispersant use in nearshore areas. 


\section{Introduction}

56

By accelerating the dispersion of oil from the sea surface into the water column, the use of dispersants (surface active agents) offers the environmental benefits of (i) diluting the oil slick in the water column (Lessard and DeMarco, 2000), (ii) reducing the threat of oiling shorelines and (iii) accelerating the bacterial degradation of oil by increasing the available surface of the oil (Tiehm, 1994; Churchill et al., 1995). However, the use of dispersant is, at the moment, subject to certain restrictions depending mainly on weather conditions, oil type, distance to the shore and/or water depth. For example in European Atlantic coast the minimum permitted water depth is $10 \mathrm{~m}$ (Chapman et al., 2007). This restriction of minimum water depths was derived from studies on the dilution of dispersed oil in shallow water and took into consideration the ecological sensitivity of nearshore areas as they are nurseries for many aquatic species. However, a field study conducted by Baca et al. (2005) suggests that, in nearshore tropical ecosystems, dispersant use minimizes the environmental damages arising from an oil spill. This Net Environmental Benefits Analysis (NEBA) highlights a positive environmental role of dispersant use in nearshore areas but it is only applicable to tropical mangroves. To the best of our knowledge no NEBA has ever been conducted in Atlantic coastal ecosystems in order to establish the current restrictions for dispersant use and policies in nearshore areas. To do so, an on-going project (DISCOBIOL project: DISpersant and response techniques for COastal areas; BIOLogical assessment and contributions to the regulation) aims at obtaining informations on the environmental impact of dispersed oil in nearshore areas.

Including in this project, this study aims at assessing the toxicity of chemically dispersed oil at concentration similar to those encountered at oil spill sites. To simulate current operational oil dispersant application, our study uses a third generation dispersant, which is the more 
recent formulations and is considered as the less toxic, the more concentrated in tensio-active and there by the most commonly used at the moment. While, most experimental studies assessed the toxicity of the dispersant itself (Adams et al., 1999; George-Ares and Clark, 2000) or the dispersed oil water-accommodated fraction (Cohen and Nugegoda, 2000; Mitchell and Holdway, 2000; Ramachandran et al., 2004; Perkins et al., 2005; Jung et al., 2009), our experimental approach simulates operational oil dispersant application, considering the presence of oil droplets in the water column. Indeed, oil droplets are suggested to be a determinant of toxicity (Brannon et al., 2006) and does so even more in nearshore areas, where natural dispersion (e.g. waves) can replace the whole oil slick from the surface in the water column (as described during the Braer oil spill by Lunel, 1995).

To reveal the toxicity of this chemically dispersed oil, several biomarkers were assessed after exposure of juvenile golden grey mullets (Liza aurata). The choice of the species is due to (i) its presence in nearshore areas during its early life stages (Gautier and Hussenot, 2005) and consequently its status of pollutants target organism (Bruslé, 1981); and to (ii) its significant role in the coastal ecosystems, since this fish species permits an important particulate organic matter transport from the salt marsh to the marine coastal waters (Lafaille et al., 1998).

In this context, the use of biomarkers seems appropriate since they are defined as "a biochemical, cellular, physiological or behavioural variation that can be measured in tissue or body fluid samples or at the level of whole organisms that provides evidence of exposure to and/or effects of one or more chemical pollutants" (Depledge et al., 1995). Hence, these ecotoxicological tools provide integrative informations, linking exposure to pollutants and the health of the monitored organisms (Sanchez and Porcher, 2009). As a consequence, other studies evaluate the toxicity to fish of a dispersed crude oil through biomarkers assessment (Cohen and Nugegoda, 2000; Jung et al., 2009; Mendonça Duarte et al., 2010) and reveal an increase of toxicity due to dispersant application. In our study, a set of complementary 
105 biomarkers, including EROD (7-ethoxy-resorufin-O-deethylase) activity implicated in phase I

106 biotransformation, total glutathione (GSH), enzymatic antioxidant activities (glutathione 107 peroxidise, GPx; catalase, CAT; superoxide dismutase, SOD; glutathione-S-transferase, GST) 108 and lipid peroxidation (LPO) were measured in the liver of golden grey mullet. These

109 biomarkers are known to be sensitive to petroleum compounds and in particular to polycyclic 110 aromatic hydrocarbons (PAHs) as described in Pan et al. (2005), Oliveira et al. (2008),

111 Nahrgang et al. (2009) and Hannam et al. (2010). Moreover, the physiological links between 112 the presence of PAHs, the production of radical oxygen species (ROS) and consequently 113 enzymatic and non-enzymatic antioxidant responses have also been described (Stegeman, 114 1987; Livingstone, 2001). The haemolytic activity of the alternative complement pathway 115 (ACH 50), an innate immune parameter that is involved in the innate humoral response, was 116 measured in the plasma of the golden grey mullets, since it is a known biomarker of 117 petroleum exposure (Bado-Nilles et al., 2009). Modulations of the antioxidant system and 118 innate immune function will be discussed with regards to the 16 PAHs USEPA priority 119 pollutants, the concentration of total petroleum hydrocarbons (TPHs) in seawater and 120 exposure biomarkers: pyrene-derived and benzo[ $[a]$ pyrene-derived biliary metabolites.

\section{Materials and methods}

2.1. Chemicals

126 An Arabian Crude Oil containing 54\% saturated hydrocarbons, 36\% aromatic hydrocarbons and $10 \%$ polar compounds, was selected for this study. Before exposure, the oil was evaporated (in a $1 \mathrm{~m}^{3}$ tank, during 24 hours) under atmospheric conditions and natural UV- 
130 (evaporation of light compounds and natural photodegradation, respectively). The resulting

131 chemical composition of the oil was 54\% saturated hydrocarbons, $34 \%$ aromatic

132 hydrocarbons and $12 \%$ polar compounds.

133 With regards to dispersant, a formulation manufactured by Total Fluides was selected based

134 on its efficiency. Dispersant was evaluated by CEDRE (CEntre de Documentation de

135 Recherche et d'Expérimentations sur les pollutions accidentelles des eaux, France) and was

136 deemed effective enough to be used in the marine environment (preliminary determined using

137 the method NF.T.90-345), non-toxic at the concentration recommended by the manufacturer

138 (preliminary determined assessing standard toxicity test: method NF.T.90-349) and

139 biodegradable. Its chemical formulation was not available for reasons of confidentiality.

140

$141 \quad 2.2$. Experimental animals

142

143 The experiment was carried out using 50 juvenile golden grey mullets (Liza aurata), which

144 were provided by Commercio Pesca Novellame Srl, Chioggia, Italy. Their average length was

$145139.0 \pm 0.7 \mathrm{~mm}$ (mean \pm standard error of the mean) and their average weight was $38.25 \pm$

$1461.22 \mathrm{~g}$.

147 The fish were acclimatized for 3 weeks in 300-L flow-through tanks (dissolved oxygen: $91 \pm$

$1482 \%$; salinity: $35 \pm 1 \% ; 15 \pm 0.1^{\circ} \mathrm{C}$, with a $12 \mathrm{~h}$ light: $12 \mathrm{~h}$ dark photoperiod in seawater free of

149 nitrate and nitrite) prior to the exposure studies. During acclimation, they were fed daily with

150 fish food (Neosupra AL3 from Le Gouessant aquaculture) but were starved for $48 \mathrm{~h}$ prior to

151 the bioassays and throughout the exposure period, in order to avoid bile evacuation from the 152 gallbladder.

153

154 2.3. Experimental design 
$156 \quad$ 2.3.1. Experimental system

158 The experimental system (Figure 1) was devised to maintain the mixture of oil and dispersant 159 as a homogenous solution. The mixture was homogenized using a funnel (at the surface of a $160300-\mathrm{L}$ seawater tank), which was linked to a Johnson L450 water pump (at the bottom of the 161 tank) in order to homogenize the mixture despite the hydrophobic nature of the oil. 162 Preliminary tests showed that, after 24 hours of homogenisation, the total petroleum 163 hydrocarbon (TPH) concentrations in the water column do not depend on water column depth, 164 suggesting the homogenous dispersion of small petroleum droplets throughout the water 165 column. The system was a static water system stocked in a temperature controlled room (15

$166{ }^{\circ} \mathrm{C}$ ), and thus exposure studies were conducted at $15 \pm 0.1{ }^{\circ} \mathrm{C}$. Other physico-chemical 167 parameters were also measured: $\mathrm{pH}(8.02 \pm 0.07)$ and dissolved oxygen $(95 \pm 1 \%)$ remained constant throughout the study.

2.3.2. Exposure conditions and exposure media

173 Control exposure medium (C) was made up using seawater provided by Oceanopolis, Brest,

174 France. The chemically dispersed (CD) oil exposure medium was made by pouring $20 \mathrm{~g}$ of 175 petroleum and $1 \mathrm{~g}$ of dispersant into the funnel of the experimental system. Dispersant alone 176 (D) exposure medium, as an internal control of $\mathrm{CD}$, was made by pouring $1 \mathrm{~g}$ of dispersant 177 into the funnel. The mechanically dispersed (MD) oil exposure medium was made by pouring $17820 \mathrm{~g}$ of petroleum into this funnel. For the water-soluble fraction of oil (WSF), in addition to 179 the funnel and the pump which were kept to maintain the same level of agitation of the 
180

181

182

183

184

185

186

seawater as for other treatments, a $20 \mathrm{~g}$ oil slick was contained using a plastic cylinder $(21 \mathrm{~cm}$ diameter) placed on the surface of the seawater $(4 \mathrm{~cm}$ below the surface and $8 \mathrm{~cm}$ above). A plastic mesh was placed at the bottom of the plastic cylinder. The spreading of the oil slick was not prevented by the plastic cylinder, as the oil slick was smaller in diameter than the plastic cylinder, therefore the experimental approach simulates the actual spreading behaviour of oil at sea. During the entire exposure period, the oil slick remained at the surface without mixing and the fish were only exposed to the soluble fraction of the oil.

None of the fish were exposed for 24 hours, while the solutions remained homogenous. The groups of 5 fish were then randomly distributed in the five experimental tanks, each tank containing an exposure medium (described above). The fish were exposed to the different media for a period of $48 \mathrm{~h}$ and the protocol was replicated so that 10 fish were exposed to each exposure medium.

At the end of the exposure period, the fish in each tank (each exposure medium) were euthanized using eugenol (4-allyl-2-methoxyphenol). To collect plasma samples, $0.2 \mathrm{~mL}$ of blood was withdrawn from the caudal vein of each fish and centrifuged (12,000 g, $10 \mathrm{~min}, 4$ ${ }^{\circ} \mathrm{C}$, Jouan). Plasma samples were stored at $-80{ }^{\circ} \mathrm{C}$. The liver and gallbladder were removed from each fish and stored at $-80{ }^{\circ} \mathrm{C}$ prior to analysis.

\subsection{TPH and PAH concentrations}

\subsubsection{TPH seawater concentrations}

The TPH concentration, which is the sum of dissolved hydrocarbon concentrations plus the amount of oil droplets, was measured for all exposure media at the beginning ( $\mathrm{T}=0 \mathrm{~h})$ and at 
the end of fish exposure ( $\mathrm{T}=48 \mathrm{~h}$ ), using the mean of three replicated measurements for each

206 time point. The seawater samples were extracted with $10 \mathrm{~mL}$ of pestipur-quality 207 dichloromethane (99.8\% pure solvent, Carlo Erba Reactifs, SDS). After separation of the 208 organic and aqueous phases, water was extracted two additional times with the same volume 209 of dichloromethane $(2 \times 10 \mathrm{~mL})$. The combined extracts were dried on anhydrous sulphate 210 and then analyzed using a UV spectrophotometer (UV-Vis spectrophometer, Unicam) at 390 211 nm, as described by Fusey and Oudot (1976).

\subsubsection{Seawater concentrations of PAHs}

PAH concentrations were assessed at the beginning $(\mathrm{T}=0 \mathrm{~h})$ and at the end of fish exposure 216 ( $\mathrm{T}=48 \mathrm{~h}$ ), using the mean of three replicated measurements for each time point. After sampling, the first step was a 24-hour settling phase to separate oil droplets and particulate matter from the seawater. Then, PAHs were extracted from the seawater using the stir bar sorptive extraction technique (SBSE - Stir bar coated with PDMS, Gerstel), and analyzed using thermal desorption coupled to capillary gas chromatography-mass spectrometry (GCMS). The GC was a HP7890 series II (Hewlett Packard, Palo Alto, CA, USA) coupled with a HP5979 mass selective detector (MSD, Electronic Impact: 70eV, voltage: $2000 \mathrm{~V}$ ). PAHs were quantified according to published procedures (Roy et al., 2005).

\subsection{Biochemical analyses}

2.5.1 Fixed wavelength fluorescence analysis

Bile samples were diluted (1:250) in absolute ethanol (VWR International). Fixed wavelength

230 fluorescence (FF) was then measured at the excitation:emission wavelength pairs 341:383 and 
380:430 nm. FF 341:383 mainly detects pyrene-derived metabolites and FF 380:430 mainly

232 detects benzo[a]pyrene-derived metabolites (Aas et al., 2000). Measurements were performed

233 in quartz cuvettes on a spectrofluorimeter (SAFAS Flx-Xenius). The FF values were 234 expressed as arbitrary units of fluorescence and the signal levels of pure ethanol were 235 subtracted.

2.5.2 Measurement of oxidative stress biomarkers

Livers were homogenized in ice-cold phosphate buffer (100 mM, pH 7.8) containing 20\% glycerol and $0.2 \mathrm{mM}$ phenylmethylsulfonyl fluoride as a serine protease inhibitor. The

241 homogenates were centrifuged at $10,000 \mathrm{~g}, 4{ }^{\circ} \mathrm{C}$, for $15 \mathrm{~min}$ and the postmitochondrial 242 fractions were used for biochemical assays. Total protein concentrations were determined using the method of (Bradford, 1976) with bovine serum albumin (Sigma-Aldrich Chemicals,

244 France) as a standard. Hepatic biomarkers assays including GSH content and activities of EROD, GST, GPx, SOD and CAT were adapted for use in microplate and, after preliminary

246 test using several dilutions, adapted for samples of liver of juvenile golden grey mullet.

247 The EROD activity was measured using the fluorimetric assay developed by Flammarion et 248 al. (1998). To summarize, $10 \mu \mathrm{L}$ of a $5 \mathrm{~g}$ proteins/L diluted sample were added to phosphate 249 buffer containing $8 \mu \mathrm{M}$ of 7-ethoxyresorufin and $0.5 \mathrm{mM}$ of NADPH. Formed resorufin was 250 quantified by fluorimetric measurement with $530 \mathrm{~nm}$ wavelength excitation and $590 \mathrm{~nm}$ 251 wavelength emission. Resorufin was used as standard, and results were expressed as nmol $252 \mathrm{resorufin} / \mathrm{min} / \mathrm{g}$ protein.

253 The GSH (total glutathione) concentration was measured according to Vandeputte et al. 254 (1994). Briefly, $10 \mu \mathrm{L}$ of TCA-deproteinized sample were mixed with phosphate buffer 255 containing $0.3 \mathrm{mM}$ NADPH and $1 \mathrm{mM}$ Ellman reagent. The enzymatic reaction was 
monitored spectrophotometrically at $405 \mathrm{~nm}$ and the results were expressed in $\mu \mathrm{mol}$ of $\mathrm{GSH} / \mathrm{g}$ of proteins.

258 The GST activity assay was conducted according to Habig et al. (1974). Briefly, $10 \mu \mathrm{L}$ of a reduced glutathione. The enzymatic reaction was monitored spectrophotometrically at $340 \mathrm{~nm}$

261 and the results were expressed in U of GST/g of proteins.

262 GPx activity was determined using $15 \mu \mathrm{L}$ of a $4.5 \mathrm{~g}$ proteins/L diluted sample according to 263 the method of Paglia and Valentine, (1967). Cumene hydroperoxide was used as the substrate 264 and enzymatic activity was assessed at $340 \mathrm{~nm}$. The results were expressed in U of GPx/g of 265 proteins.

266 SOD activity was measured using the assay developed by Paoletti et al. (1986). Briefly, the 267 inhibition of NADH $(350 \mu \mathrm{M})$ oxidation by $20 \mu \mathrm{L}$ of a $0.25 \mathrm{~g}$ proteins/L diluted sample was 268 monitored at $340 \mathrm{~nm}$. The results were presented in $\mathrm{U}$ of SOD/mg of proteins.

269 CAT activity was monitored using the method previously described by Babo and Vasseur 270 (1992). Briefly, $0.08 \mathrm{~g}$ proteins/L diluted samples were mixed (v:v) with $28 \mathrm{mM}$ hydrogen 271 peroxide. The kinetics of hydrogen peroxide degradation were assessed at $280 \mathrm{~nm}$ and the 272 results were expressed in $\mathrm{U}$ of $\mathrm{CAT} / \mathrm{mg}$ of proteins.

2.5.3 Lipid peroxidation (LPO) determination

Lipid peroxidation levels were assessed via malondialdehyde (MDA) content determined 277 using a commercially available MDA assay kit (Oxis International MDA assay kit). The method was based on the reaction of a chromogenic reagent, $\mathrm{N}$-methyl-2-phenylindole, with

279 MDA at $45{ }^{\circ} \mathrm{C}$. The blue product was quantified by measuring absorbance at $586 \mathrm{~nm}$ (Gérard280 Monnier et al., 1998). 
282 2.5.4 Determination of the alternative pathway of plasma complement activity

284 Determination of the alternative pathway of plasma complement activity was carried out by 285 haemolytic assay with rabbit red blood cells (RRC, Biomérieux, France) as described by 286 Yano (1992) and adapted to microtitration plates. Plasma samples, diluted to 1/80 in EGTA287 Mg-GVB buffer, were added in increasing amounts, from 10 to $100 \mu \mathrm{L}$ per well. The wells 288 were then filled with EGTA-Mg-GVB buffer to a final volume of $100 \mu \mathrm{L}$. Finally, $50 \mu \mathrm{L}$ of a 289 suspension containing $2 \%$ rabbit red blood cells were added to each well. Control values of $290 \quad 0 \%$ and $100 \%$ haemolysis were obtained using $100 \mu \mathrm{L}$ of EGTA-Mg-GVB buffer and $100 \mu \mathrm{L}$ 291 of non-decomplemented trout haemolytic serum at 1/50 in ultra pure water respectively.

292 Samples were incubated for 1 hour at $20^{\circ} \mathrm{C}$. The microplates were centrifuged $(400 \mathrm{~g}, 5 \mathrm{~min}$, 293 $4{ }^{\circ} \mathrm{C}$, Jouan). Then, $75 \mu \mathrm{L}$ of supernatant from each well were transferred with $75 \mu \mathrm{L}$ of 294 phosphate buffer saline (Biomérieux, France) into another 96-well microplate. The absorbance $(540 \mathrm{~nm})$ was read in a spectrofluorimeter (SAFAS Flx-Xenius) and the number of $\mathrm{ACH} 50$ units per mL of plasma was determined by reference to $50 \%$ haemolysis.

2.6 Statistical analysis

The statistical analysis was carried out using XLstat 2007 software. The assumptions of 301 normality and homoscedasticity were verified using the Kolmogorov-Smirnov and Cochran 302 tests, respectively. Firstly, Student's t-tests were conducted, for each variables (fixed wavelength fluorescence, EROD activity, total glutathione concentration, hepatic oxidative stress biomarkers, lipid peroxidation, haemolytic activity of alternative complement pathway) in order to highlight significant differences between both experimental replicates of each 
exposure media. No significant difference was found, thereby, both replicates were considered as one homogenous group of ten individuals. A factorial analysis of variance (oneway ANOVA) was performed in order to assess the effects of the several exposure conditions. This statistical analysis was followed by the Tukey post-hoc test to detect significant differences between groups. The significance of the results was ascertained at $\alpha=0.05$. The

311 results were expressed as means \pm s.e.m. (standard error of the mean) corresponding to groups 312 of ten fish $(\mathrm{n}=10)$.

\section{Results}

No fish mortality was observed during the experiments. Moreover no TPH or PAH was detected in the control and dispersant exposure media. The TPH concentration measured in the CD (chemically dispersed oil) and MD (mechanically dispersed oil) groups corresponded to that encountered under oil spill situations (for instance, 1 to $100 \mathrm{mg} / \mathrm{L}$ of total petroleum

321 hydrocarbons were measured in coastal waters around Shetland during the Braer oil spill, as

322 reported by Lunel,1995). No oil slick was observed in either the CD or MD exposure media, suggesting that the energy in the experimental system was sufficient to disperse the oil slick.

324 These observations validated the experimental procedure.

3.1. Total petroleum hydrocarbon (TPH) and polycyclic aromatic hydrocarbon (PAH) 327 concentration in seawater.

The TPH concentrations of oil were higher in media with dispersant compared to without, and 330 the lowest concentration was observed in the WSF (water soluble fraction of oil) medium, in 
which only dissolved compounds were present in the seawater column. In the CD medium,

332 the TPH concentration (Table 1) was $39 \mathrm{mg} / \mathrm{L}$ at the beginning of the exposure period $(\mathrm{T}=0$

$333 \mathrm{~h})$ and $25 \mathrm{mg} / \mathrm{L}$ at the end of the exposure period $(\mathrm{T}=48 \mathrm{~h})$, giving a percentage decrease of 36

$334 \%$. In the MD medium, the TPH concentration was $13 \mathrm{mg} / \mathrm{L}$ at the beginning of the exposure 335 period $(\mathrm{T}=0 \mathrm{~h})$ and $9 \mathrm{mg} / \mathrm{L}$ at the end of the exposure period $(\mathrm{T}=48 \mathrm{~h})$, giving a percentage 336 decrease of $29 \%$. The TPH concentration could not be determined in the WSF medium since 337 it was too low to be detected using spectrophotometry.

338 According to spectrophotometry as well as gas chromatography coupled with mass 339 spectrometry, petroleum compounds and PAHs were not detected in the D (Dispersant) or C 340 (Control) media.

341 In terms of the sum of 16 parent and alkylated USEPA PAHs ( $\Sigma \mathrm{PAH})$ concentrations, the CD 342 medium contained $43.98 \mu \mathrm{g} / \mathrm{L}$, at the beginning of the experiment, then $26.34 \mu \mathrm{g} / \mathrm{L}$ after 48 343 hours, giving a percentage decrease of $40 \%$. For MD, the percentage decrease was $48 \%$ : the $344 \Sigma$ PAH concentration at $\mathrm{T}=0 \mathrm{~h}$ was $39.09 \mu \mathrm{g} / \mathrm{L}$ and at $\mathrm{T}=48 \mathrm{~h}$ it was $20.63 \mu \mathrm{g} / \mathrm{L}$. WSF values 345 were lower when compared to both the CD and MD values, with a $\Sigma$ PAHs concentration at $346 \mathrm{~T}=0 \mathrm{~h}$ of $5.16 \mu \mathrm{g} / \mathrm{L}$ and at $\mathrm{T}=48 \mathrm{~h}$ of $0.47 \mu \mathrm{g} / \mathrm{L}$, corresponding to a drastic decrease $(91 \%)$.

347 Regarding the concentration of 16 USEPA PAHs (alkylated and parents) in seawater during 348 CD, MD and WSF exposures (Table 2), it appears that two- or three-ring PAH compounds 349 (specifically, naphthalene alkylated compounds) were dominant when compared to heavier 350 PAHs ( $\geq$ four rings). Regarding the variation over time in PAH concentration, it appears that 351 light PAHs such as naphthalene (parent and alkylated) decreased during CD, MD and WSF 352 exposure (with the exception of fluorene for $\mathrm{CD}$ exposure) while the concentrations of 353 heavier PAHs remained relatively stable or increased (e.g. chrysene). 
357 With regards to the levels of benzo[a]pyrene-type metabolites, which were measured by 358 fluorescence intensity (FF 380:430), CD and MD exposures led to significantly higher values, 359 compared to the values obtained in control fish (C). The intensity of fluorescence did not 360 significantly differ between the C, WSF and D groups of fish, even though WSF exposure 361 seemed to increase the intensity (Figure 2a).

362 With regards to the levels of pyrene-type metabolites (Figure 2b), which were measured by 363 fluorescence intensity (FF 341:383), CD and MD exposure led to significantly higher values 364 when compared to values obtained in control fish (C). The intensity of fluorescence did not 365 significantly differ between the C, WSF and D groups of fish, even though WSF exposure 366 seemed to increase the intensity. The intensity of fluorescence following CD exposure was 367 significantly different to that following WSF and D exposure while it appears that MD exposure did not induce an increase in fluorescence compared to WSF and D exposure.

3.3. EROD (7-ethoxy-resorufin-O-deethylase) activity, Total glutathione content and hepatic

371 oxidative stress biomarkers

EROD demonstrated no significant difference between the exposure conditions (Figure 3) and was characterized by a high intragroup variability that could reflect differences in biotransformation processes between organisms.

376 The concentration of GSH (total glutathione, Figure 4) significantly decreased after exposure 377 to $\mathrm{CD}(45.35 \pm 8.65)$ and $\mathrm{MD}(53.18 \pm 10.04)$, compared to the control group (130.50 \pm 32.64), while no significant difference was observed after exposure to WSF $(90.51 \pm 23.11)$ or D (108.44 \pm 22.86$)$. When CD and MD were compared with WSF and D, no significant 
difference was revealed even though the GSH content in the WSF and D groups seemed

381 higher than in the CD and MD groups.

382 No significant difference between exposure conditions was recorded for antioxidant enzyme 383 activities (i.e. GST, GPx, SOD and CAT) (Figure 5).

\subsection{Lipid peroxidation (LPO)}

As for antioxidant enzymes, LPO demonstrated no significant difference between the exposure conditions (Figure 6). However, LPO was characterized by a high intragroup variability (especially for WSF, CD and MD exposure media) that could reflect differences in sensitivity between organisms.

3.5. Haemolytic activity of alternative complement pathway (ACH 50)

The results are presented in Figure 7. As for antioxidant enzymes, ACH 50 demonstrated no significant difference between the exposure conditions. Haemolytic activity appeared to be

396 lower after CD exposure and higher after MD exposure.

\section{Discussion}

The aim of this study was to accurately simulate operational oil dispersant application and to assess its toxicity. An experimental system providing mixing energy (described in section 2.3.1) was necessary for this purpose: to achieve the dispersion of crude oil through operational dispersant application, seawater energy is necessary (Merlin, 2005). Readers must

404 take into account that the results obtained (and discussed below), through this experimental 
approach, are available only for a given mixing energy (the mixing energy induces by the waterpump). However, extrapolation of results from the experimental approach to the oil spill operations is possible. Indeed, meteorological conditions during the Braer oil spill (Wind force 7 to 10, Lunel, 1995) were the most propitious to dispersed oil, among most of the meteorological conditions during oil spills. While a dispersion of the whole oil was maintained for more than one week, other oil spills, in offshore areas, exposed an unstable 411 dispersion of oil slick with a rapid decrease of concentration in 2-5 hours (Lessard and 412 Demarco, 2000). Our experimental approach is situated between these two opposite scenarios 413 (decrease of concentration on a 48 hours period, discussed in 4.1) and thus can be considered 414 as a possible one. Moreover, acccording to CEDRE observations during oil spill response in 415 nearshore area, 4 tide cycles (48h) are sufficient to totally disperse the oil slick, so that no 416 petroleum is present after this period. This suggests that an exposure of $48 \mathrm{~h}$ seems to be accurate.

418 The fish were exposed to (i) a chemically dispersed oil (simulating dispersant application), (ii) 419 dispersant alone in sea water (as an internal control of chemically dispersed oil), (iii) 420 mechanically dispersed oil (simulating natural dispersion), (iv) water-soluble fraction of oil 421 (simulating an oil slick confinement response technique) and to (v) sea water alone (control condition).

4.1. Total petroleum hydrocarbon $(\mathrm{TPH})$ and polycyclic aromatic hydrocarbon $(\mathrm{PAH})$ concentrations in seawater.

The energy supplied by the experimental system was the same for the five exposure media. However, our results show that the TPH concentration in the water column was higher in CD than in $\mathrm{MD}$ at $\mathrm{T}=0 \mathrm{~h}$ and $\mathrm{T}=48 \mathrm{~h}$. This finding and our observations, suggest that oil adheres 
more to the experimental system in the MD exposure medium than in the $\mathrm{CD}$ exposure

431 medium. When extrapolated to field operations in the shallow water of nearshore areas, the

432 results show that the application of dispersants would promote higher concentrations of TPH

433 in the water column but would decrease the adherence to substrates (seagrass beds, sediments

434 etc...). This result is in accordance with Baca et al. (2005) and shows that dispersant

435 application increases the exposure to TPH for pelagic organisms living in the water column

436 (as golden grey mullets), while decreases the exposure to TPH for benthic organisms.

437 Unlikely TPH concentration, the difference of the sum of PAH concentrations between CD

438 and MD exposures is low (slightly higher in $\mathrm{CD}$ exposure). The sum of PAH concentration is

439 relevantly lower in WSF exposure medium than in CD and MD exposures (at $\mathrm{T}=0 \mathrm{~h}$ and $\mathrm{T}=48$

$440 \mathrm{~h}$ ): as a consequence of dispersion, oil droplets have a larger surface-to-volume ratio than an

441 oil slick, and this would accelerate the solubilization of PAHs in seawater. Consideration

442 must also be given to the fact that the sum of PAHs decreased slightly in the CD and MD

443 exposure media while drastically decreased during the 48 hours of WSF exposure media. The

444 solubilization and volatilization/photolysis of PAHs are two opposing processes that

445 determine the distribution and the residence time of PAHs in seawater (Schwarzenbach et al.,

446 2003). In this case, it can be hypothesized that the dispersion of oil (CD and MD exposure)

447 triggers the solubilization of PAHs from oil droplets into the seawater, which relatively

448 compensates for the volatilization/photolysis of PAHs that occurs during the exposure.

449 Inversely the solubilization of PAHs from the oil slick to the seawater (WSF exposure) was

450 not high enough to compensate for the loss of PAHs due to volatilization/photolysis. Another

451 explanation could be that PAH loss is due to absorption by golden grey mullets as it is

452 suggested in literature for other organisms (Le Floch et al. 2003; Goanvec et al. 2008).

453 With regards to the 16 USEPA PAHs (alkylated and parent), the results show that light PAHs

454 (two to three rings) were predominant in the WSF, CD and MD exposure media at $\mathrm{T}=0 \mathrm{~h}$ and 
$\mathrm{T}=48 \mathrm{~h}$. This observation is consistent with the current theory that the aqueous solubility

456 increases as the molecular weight of PAHs decreases (Neff, 1979). Moreover, with the 457 exception of fluorene, the concentrations of light PAHs decreased during the experiment 458 while the concentration of heavy PAHs remained stable (cf. Indeno[1,2,3-cd]pyrene and 459 Dibenzo $[a, h]$ anthracene in Table 2), a phenomenon probably attributable to the 460 volatilization/photolysis of light PAHs (Schroeder and Lane, 1988).

4.2. Fixed wavelength fluorescence analysis of biliary PAH metabolites

The fixed wavelenght fluorescence of fish biliary metabolites has been used as a PAHs exposure biomarker in many studies (Aas et al., 2000; Barra et al., 2001; Kopecka-Pilarczyk and Correia, 2009; Insausti et al., 2009).

In our study pyrene-derived fluorescence was significantly higher under MD and CD

exposures than under control exposure (C). However, only fluorescence under CD exposure was significantly higher than WSF and D exposures, which show that the exposure to pyrene was higher when the oil was chemically dispersed. These results are consistent with the alkylated fluoranthenes/pyrenes seawater concentration at $\mathrm{T}=48 \mathrm{~h}$ since this was higher under $\mathrm{CD}$ exposure. However at $\mathrm{T}=0 \mathrm{~h}$, no pyrene (alkylated or parent) was detected under $\mathrm{CD}$.

473 Concerning the benzo[ $[a]$ pyrene-type metabolites, fluorescence was higher under CD and MD 474 exposures than for the other exposure groups (WSF, D, C), indicating a higher bioavailability 475 of this PAH (and its derived type). Even though the relative fluorescence was higher under 476 WSF exposure than in other conditions ( $\mathrm{D}$ and $\mathrm{C}$ ), the difference was not significant. These 477 results are consistent with the benzo[a]pyrene concentrations measured in the seawater, since 478 the concentration of this PAH was similar for CD and MD exposures and lower for WSF 479 exposure (at $\mathrm{T}=0 \mathrm{~h}$ and $\mathrm{T}=48 \mathrm{~h}$ ). Benzo $[a]$ pyrene is considered carcinogenic and is a radical 
oxygen species producer through its role as a P450 mixed-function oxidase (MFO) inducer

481 (Lemaire-Gony and Lemaire, 1993). This result is of importance because it reveals the potentially high toxicity of $\mathrm{CD}$ and $\mathrm{MD}$ exposures when compared to other conditions.

For both metabolite types, the relative fluorescence revealed a higher exposure of fish to

PAHs under CD exposure (compared to WSF), probably resulting from the higher PAH concentrations in the seawater. The results are consistent with the literature; indeed

Ramachandran et al. (2004) showed that oil dispersant increases PAHs uptake by fish exposed

to crude oil. Moreover Jung et al. (2009) showed that hydrocarbons metabolites in bile from

fish exposed to crude oil treated with dispersant were significantly higher compared with fish exposed to crude oil alone.

To the best of our knowledge no studies have been conducted in order to allow the 491 comparison between the toxicity of an oil slick dispersed with turbulent mixing energy and dispersant (CD) to an oil slick dispersed only with turbulent mixing energy (MD). Even if benzo $[a]$ pyrene derived metabolites levels seem to be slightly lower in MD exposure than in CD exposure, no significant difference was highlighted. This is in accordance with the 495 benzo $[a]$ pyrene concentrations in seawater (no difference between $\mathrm{CD}$ and MD exposure). 496 However, for pyrene derived metabolites, while a significant difference was observed between CD and WSF, no difference was observed between MD and WSF exposure. This 498 finding is in accordance with the pyrene concentration in sea water: alkylated 499 fluoranthenes/pyrenes seawater concentration (at $\mathrm{T}=48 \mathrm{~h}$ ) was higher under CD exposure.

503 Since the eighties, EROD activity is commonly used to reveal PAHs biotransformation 504 (Addison and Payne, 1987) and thereby a large body of literature permits comparison of our 
results to other studies. Furthermore, since EROD activity is involved in phase I

506 biotransformation of xenobiotics, the modulation of this biomarker in response to PAHs is more precociously observed than the increase of PAHs biliary metabolites (described above).

508 By the way EROD activity measurement gives an idea of organism short term defence against 509 the xenobiotics.

510 Ramachandran et al. (2004) and Jung et al. (2009) showed an increase of EROD activity 511 following chemically dispersed oil exposure. However, our study did not show an EROD 512 activity increase while a PAHs biliary metabolites increase was observed following dispersed crude oil exposure. A reason for this lack of significance could be the low sensitivity to PAHs

514 of EROD activity, when compared to biliary metabolites sensitivity (Camus et al., 1998).

4.4. Total glutathione content

The results obtained for total glutathione content in the liver of Liza aurata after $48 \mathrm{~h}$ confirmed previous results concerning biliary metabolites contents since a significant 520 difference was found between dispersed oil exposure (CD and MD) and the control condition. 521 These results are consistent with the literature since Almroth et al. (2008) showed a significance decrease in total glutathione in corkwing wrasse (Symphodus melops) exposed to contaminated PAHs sites. The total glutathione content, which corresponds to reduced plus oxidized glutathione (GSH+GSSG), was lower in both conditions (CD and MD), although

525 GST activity did not change. This finding shows that depletion was not due to glutathione 526 conjugation (phase II detoxification) since an increase in GST should be concomitant with 527 conjugation. Nevertheless, it is possible that the decrease in total glutathione was due to 528 inhibition of the GSH synthesis rate by contaminants, as suggested in Canesi et al. (1999), in 529 Wang et al. (2008) and in Zhang et al. (2004) on freshwater crabs, mussels and goldfish, 
respectively. Another explanation could be that, in the process of detoxification, reduced

531 glutathione chelated the heavy metals contained in petroleum (mainly vanadium and nickel) so that GS-V or GS-Ni binding complexes are formed (Sies, 1999). These complexes cannot be assessed through biochemical analysis and contributed to the observed reduction in total

534 glutathione content. However, according to low heavy metals concentration in common crude 535 oil (e.g. $109.9 \mathrm{mg} / \mathrm{L}$ of Vanadium and $71.5 \mathrm{mg} / \mathrm{L}$ of Nickel, Salra Amoli et al., 2006) and the 536 short exposure period of our experiment, this explanation seems to be less accurate.

537 So, although the mechanism is not fully understood, this study shows that total glutathione is 538 depleted, suggesting, for CD and MD exposures, a reduction in the first line cellular defence, 539 since glutathione is involved in several detoxification reactions. Indeed, conjugation of 540 glutathione to contaminants can prevent them from interacting deleteriously with other 541 cellular components, enabling the organism to cope with the contaminated environment 542 (Maracine and Segner, 1998).

543 Moreover Ringwood and Conners (2000) showed that gonadal depletion of glutathione 544 induces a decrease in reproductive success in oyster. Even if this study was conducted in 545 oyster, this finding suggests that a link between the total glutathione pool and the organism 546 fitness could exist. Since our study demonstrated a depletion of the total glutathione pool in 547 the liver of juveniles golden grey mullets, it would also be interesting to assess the total 548 glutathione in the gonads of adult fish.

$550 \quad 4.5$ Antioxidant enzyme activity and lipid peroxidation (LPO).

552 Antioxidant enzyme activity has been shown to be modulated in response to short term $(\leq 48$ 553 h) contaminants exposure in different targets organs of fish (Ahmad et al., 2005; Sun et al., 554 2006; Modesto and Martinez, 2010) and especially to short term PAHs exposure in the liver 
of golden grey mullet (Oliveira et al., 2008). However, in our study, results concerning antioxidant enzyme activity showed no significant differences between exposure conditions, suggesting that oxidative stress was absent.

LPO was measured via the malondialdehyde content in the liver and revealed the targeting of cell membranes by radical oxygen species (ROS), thus altering membrane fluidity, compromising membrane integrity, inactivating membrane-bound enzymes and disrupting

561 surface receptor molecules. In Ahmad et al. (2005) and in Oliveira et al (2008), a LPO increase was observed in fish gills after $48 \mathrm{~h}$ of contamination and in fish livers after $16 \mathrm{~h}$ of contamination, respectively. In our study the high intragroup variability, when compared to

564 other studies (Oliveira et al., 2008; Kopecka-Pilarczyk and Correia, 2009), induced a lack of 565 significance, confirming the notion that oxidative stress was absent. However it should be 566 stated that, for exposure conditions containing petroleum (CD, MD, WSF) a high intragroup 567 variability was observed whereas a lower variability was observed following Control (C) and single dispersant (D) exposure. This observation suggests a difference of oxidative stress 569 between the individuals exposed to conditions containing petroleum.

570 Oliveira et al. (2008) evaluated oxidative stress using, as in our study, LPO and antioxidant 571 enzyme activity in the liver of Liza aurata exposed to a PAH (phenanthrene). They found a significant difference in these biomarkers, but the concentrations of phenanthrene were 50 to 5731300 times higher than in our study. 4.6 Haemolytic activity of alternative complement pathway (ACH 50) The innate immune function has also been used as a biomarker of PAH toxicity (Seeley and 578 Weeks-Perkins, 1997; Carlson et al., 2004). The complement system of teleost fish is a 579 powerful defence system since it is involved in important immune functions that are pivotal to 
the recognition and clearance of microbes (Boshra et al., 2006). Moreover, the haemolytic

581 activity of the alternative complement pathway has been shown to be a suitable biomarker of 582 PAHs contamination in teleost fish (Bado-Nilles et al., 2009). On this basis, the alternative 583 complement pathway was chosen since its functional degradation by exposure to petroleum 584 compounds could reveal an alteration in fish health.

585 In our study no significant difference was found between the control condition and 586 contaminant exposures, even though the haemolytic activity seemed to be lower following 587 CD exposure. Bado-Nilles et al. (2009) found significant differences between contaminated 588 and control fish, for a sum of PAH concentrations that was lower than in our study, but for 589 longer exposure times, suggesting that alteration of haemolytic activity could have been 590 observed after more than $48 \mathrm{~h}$ of exposure.

591

\section{Conclusion}

Based on fixed wavelength fluorescence analysis of biliary PAH metabolites, the results from this study show higher exposure for dispersed crude oil (CD and MD) than for other types of 596 contaminant exposure. Also, the total glutathione content, described as a first line cellular defence against contaminants, was significantly reduced under dispersed oil exposures. Antioxidant enzymes did not show any responses to the contamination. EROD activity, lipid peroxidation and the haemolytic activity of the complement system also did not respond when

600 fish were exposed to contaminants.

601 These results demonstrate a significant response of biomarkers to chemically dispersed oil, 602 when compared to a non-dispersed oil slick (water-soluble fraction of oil), suggesting that oil

603 slicks must not be dispersed when containment and recovery can be conducted at the oil spill 604 site (low mixing energy of seawater). This finding is in accordance with an important body of 
605 literature: many studies show an increase of PAHs toxicity to fish following dispersant 606 application (Perkins et al., 1973; Cohen and Nugegoda, 2000; Ramachandran et al., 2004; Lin 607 et al., 2009). On the other hand, no significant difference in the response of biomarkers was 608 observed between chemically and mechanically dispersed oil. This finding suggests that when 609 containment and recovery cannot be conducted (high mixing energy of seawater) the 610 application of dispersant in nearshore areas is no more toxic than the natural dispersion 611 (wave, current, swell).

612 To conclude, the results of this study are of interest with regards establishing a framework for 613 dispersant use and policies in nearshore areas since they are part of a current project: 614 DISCOBIOL project (DISpersant and response techniques for COastal areas: BIOLogical 615 assessement and contributions to the regulation). Initially, this project intends to assess the 616 toxicity of chemically dispersed oil to several species living in nearshore areas (Crassostera 617 gigas, Mytilus edulis, Scophtalmus maximus, Dicentrarchus labrax and Liza aurata). For this 618 reason, organisms were exposed to oil in the water column. However, since dispersed crude 619 oil can interact with other components of nearshore area habitats, such as mudflats, further 620 studies must be conducted in order to better evaluate the net environmental benefits of 621 dispersant application in nearshore areas.

\section{Acknowledgements}

626 This study was supported by a PhD grant from the Conseil Général of the Charente-Maritime. 627 The Agence Nationale de la Recherche and especially Michel Girin and Gilbert Le Lann are 628 acknowledged for financial support for the project 'DISCOBIOL', managed by F. X. Merlin. 629 The authors also acknowledge Total Fluides and Innospech for providing chemicals. Special 
630 thanks go to Julie Lucas and Marion Menguy for their help and assistance during the study

631 and during the experimental procedures.

632

633

634 References

635

636 Aas, E., Baussant, T., Balk, L., Liewenborg, B., Andersen, O.K., 2000. PAH metabolites in bile, cytochrome P4501A and DNA adducts as environmental risk parameters for chronic oil exposure: a laboratory experiment with Atlantic cod. Aquat. Toxicol. 51, 241-258.

639

640 Adams, G.G., Klerks, P.L., Belanger, S.E., Dantin, D., 1999. The effect of the oil dispersant 641 omni-clean on the toxicity of fuel oil $n^{\circ} 2$ in two bioassays with the sheepshead minnow cyprinodon variegatus. Chemosphere 39, 2141-2157.

643

644 Addison, R.F., Payne, J.F., 1987. Assessment of hepatic mixed function oxidase induction in 645 winter flounder (Pseudopleuronectes americanus) as a marine petroleum pollution monitoring 646 technique, with an appendix describing practical field measurements of MFO activity. Can. 647 Tech. Rep. Fish Aquat. Sci. nº 150.

648

649 Almroth, B.C., Sturve, J., Stephensen, E., Holth, T.F., Förlin, L., 2008. Protein carbonyls and 650 antioxidant defenses in corkwing wrasse (Symphodus melops) from a heavy metal polluted 651 and a PAH polluted site. Mar. Environ. Res. 66, 271-277.

652

653 Babo, S., Vasseur, P., 1992. In vitro effects of Thiram on liver antioxidant enzyme activities 654 of rainbow trout (Oncorhynchus mykiss). Aquat. Toxicol. 22, 61-68. 
656 Baca, B., Ward, G.A., Lane, C.H., Schuler, P.A., 2005. Net environmental benefit analysis 657 (NEBA) of dispersed oil on nearshore tropical ecosystems derived from International oil spill conference, Miami, Florida, USA, pp. 1-4.

659

660 Bado-Nilles, A., Quentel, C., Auffret, M., Le Floch, S., Gagnaire, B., Renault, T., Thomas661 Guyon, H., 2009. Immune effects of HFO on European sea bass, Dicentrarchus labrax, and 662 Pacific oyster, Crassostrea gigas. Ecotoxicol. Environ. Saf. 72, 1446-1454.

663

664 Barra, R., Sanchez-Hernandez, J.C., Orrego, R., Parra, O., Gavilan, J.F., 2001. Bioavailability 665 of PAHs in the Biobio river (Chile): MFO activity and biliary fluorescence in juvenile 666 Oncorhynchus mykiss. Chemosphere 45, 439-444.

667

Boshra, H., Li, J., Sunyer, J.O., 2006. Recent advances on the complement system of teleost 669 fish. Fish Shellfish Immunol. 20, 239-262.

670

671 Bradford, M.M., 1976. A rapid sensitive method for the quantitation of microgram quantities of protein utilizing the principle of protein-dye binding. Analytical Biochemistry 72, 248-254.

673

674 Brannon, E.L., Collins, K.M., Brown, J.S., Neff, J.M., Parker, K.R., Stubblefield, W.A., 2006. 675 Toxicity of weathered "Exxon Valdez" crude oil to pink salmon embryos. Environ. Toxicol. 676 and Chem. 25, 962-972.

677

678 Bruslé, J., 1981. Food and feeding in grey mullets. in: Oren O.H. (ed.), Aquaculture of grey

679 mullets. Cambridge University Press, Cambridge, pp. 185-217. 
681 Camus, L., Aas, E., Børseth, J.F., 1998. Ethoxyresorufin-O-deethylase activity and fixed

682

683

684

685

686

687

688

689

690

691

692

693

694

695

696

697

698

699

Depledge, M.H., Aagaard, A., Györkös, P., 1995. Assessment of trace metal toxicity using 704

wavelength fluorescence detection of PAHs metabolites in bile in turbot (Scophthalmus maximus L.) Exposed to a dispersed topped crude oil in a Continuous Flow System. Mar. Environ. Res. 46, 29-32.

Canesi, L., Viarengo, A., Leonzio, C., Filippelli, M., Gallo, G., 1999. Heavy metals and glutathione metabolism in mussel tissues. Aquat. Toxicol. 46, 67-76.

Carlson, E.A., Li, Y., Zelikoff, J.T., 2004. Suppressive effects of benzo[a]pyrene upon fish immune function: Evolutionarily conserved cellular mechanisms of immunotoxicity. Mar. Environ. Res. 58, 731-734.

Chapman, H., Purnell, K., Law, R.J., Kirby, M.F., 2007. The use of chemical dispersants to combat oil spills at sea: A review of practice and research needs in Europe. Mar. Pollut. Bull. $54,827-838$.

Churchill, P.F., Dudley, R.J., Churchill, S.A., 1995. Surfactant-enhanced bioremediation. Waste Manag. 15, 371-377.

Cohen, A. M., Nugegoda, D., 2000. Toxicity of Three Oil Spill Remediation Techniques to the Australian Bass (Macquaria novemaculeata). Ecotoxicol. Environ. Saf. 47, 178-185. molecular, physiological and behavioural biomarkers. Mar. Pollut. Bull. 31, 19-27. 
706 Flammarion, P., Migeon, B., Garric, J., 1998. Statistical analysis of cyprinid ethoxyresorufin-

707 O-deethylase data in a large French watershed. Ecotoxicol. Environ. Saf. 40, 144-153.

708

709 Fusey, P. and Oudot, J. 1976. Comparaison de deux méthodes d'évaluation de la 710 biodégradation des hydrocarbures in vitro. Mater. U. Organ., 4, p.241-251.

Gautier, D., Hussenot, J. (Eds.), 2005. Les mulets des mers d'Europe. Synthèse des connaissances sur les bases biologiques et les techniques d'aquaculture. Ifremer, Paris.

George-Ares, A., Clark, J.R., 2000. Aquatic toxicity of two Corexit dispersants. Chemosphere 40, 897-906.

Gérard-Monnier, D., Erdelmeier, I., Régnard, K., Moze-Henry, N., Yadan, J., Chaudière, J., 1998. Reactions of 1-Methyl-2-phenylindole with Malondialdehyde and 4-Hydroxyalkenals. Analytical Applications to a Colorimetric Assay of Lipid Peroxidation. Chem. Res. Toxicol. 11, 1176-1183.

Goanvec, C., Theron, M., Lacoue-Labarthe, T., Poirier, E., Guyomarch, J., Floch, S.L.,

724 Laroche, J., Nonnotte, L., Nonnotte, G., 2008. Flow cytometry for the evaluation of 725 chromosomal damage in turbot Psetta maximus (L.) exposed to the dissolved fraction of 726 heavy fuel oil in sea water: a comparison with classical biomarkers. J. Fish. Biol. 73, 395-413. enzymatic step in mercapturic acid formation. J. of Biol. Chem. 249, 7130-71392. 
731 Hannam, M.L., Bamber, S.D., Galloway, T.S., John Moody, A., Jones, M.B., 2010. Effects of

732 the model PAH phenanthrene on immune function and oxidative stress in the haemolymph of

733 the temperate scallop Pecten maximus. Chemosphere 78, 779-784.

734

735 Insausti, D., Carrasson, M., Maynou, F., Cartes, J.E., Solé, M., 2009. Biliary fluorescent

736 aromatic compounds (FACs) measured by fixed wavelength fluorescence (FF) in several marine fish species from the NW Mediterranean. Mar. Pollut. Bull. 58, 1635-1642.

Jung, J.H., Yim, U.H., Han, G.M., Shim, W.J., 2009. Biochemical changes in rockfish,

740 Sebastes schlegeli, exposed to dispersed crude oil. Comparative Biochemistry and Physiology

741 Part C: Toxicology \& Pharmacology 150, 218-223.

742

743 Kopecka-Pilarczyk, J., Correia, A.D., 2009. Biochemical response in gilthead seabream

744 (Sparus aurata) to in vivo exposure to a mix of selected PAHs. Ecotoxicol. Environ. Saf. 72, $745 \quad 1296-1302$.

Laffaille, P., Brosse, S., Feunteun, E., Baisez, A., Lefeuvre, J.C., 1998. Role of fish communities in particulate organic matter fluxes between salt marshes and coastal marine waters in the Mont Saint-Michel Bay. Hydrobiologia 373/374, 121-133.

751 Le Floch, S., Guyomarch, J., Merlin, F., Borseth, J., Corre, P.L., Lee, K., 2003. Effects of oil and bioremediation on mussel (Mytilus edulis L.) growth in mudflats. Environ. Technol. 24, 1211-1219. 
Lemaire-Gony, S., Lemaire, P., 1993. Interactive effects of cadmium and benzo(a)pyrene on

756 cellular structure and biotransformation enzymes of the liver of the European eel Anguilla anguilla. Aquat. Toxicol. 22, 145-160.

758

759

Lessard, R.R., DeMarco, G., 2000. The Significance of Oil Spill Dispersants. Spill Sci.

760 Technol. Bull. 6, 59-68.

761

762

Lin, C.Y., Anderson, B.S., Phillips, B.M., Peng, A.C., Clark, S., Voorhees, J., 2009.

763 Characterization of the metabolic actions of crude versus dispersed oil in salmon smolts via

NMR-based metabolomics. Aquatic. Toxicol. 95, 230-238.

Livingstone, D.R., 2001. Contaminant-stimulated Reactive Oxygen Species Production and

Oxidative Damage in Aquatic Organisms. Mar. Pollut. Bull. 42, 656-666.

768

769

Lunel, T., 1995. The Braer oil spill: oil fate governed by dispersion International oil spill conference, Long Beach, California, USA

771

Maracine, M., Segner, H., 1998. Cytotoxicity of metals in isolated fish cells: Importance of the cellular glutathione status. Comparative Biochemistry and Physiology Part A 120, 83-88.

775 Mendonça Duarte, R., Tomio Honda, R., Luis Val, A., 2010. Acute effects of chemically 776 dispersed crude oil on gill ion regulation, plasma ion levels and haematological parameters in tambaqui (Colossoma macropomum). Aquat. Toxicol. 97, 134-141. 
779 Merlin, F.X., 2005. Traitement aux dispersants des nappes de pétrole en mer. CEDRE

780 (CEntre de Documentation de Recherche et d'expérimentations sur les pollutions accidentelles 781 des eaux), Brest, France.

783 Mitchell, F.M., Holdway, D.A., 2000. The acute and chronic toxicity of the dispersants 784 Corexit 9527 and 9500, water accommodated fraction (WAF) of crude oil, and dispersant 785 enhanced WAF (DEWAF) to Hydra viridissima (green hydra). Water Res. 34, 343-348.

786

787 800 Environ. 396, 70-78.

801

802

803 294-299.
Modesto K.A., Martinez C.B.R., 2010. Roundup causes oxidative stress in liver and inhibits acetylcholinesterase in muscle and brain of the fish Prochilodus lineatus. Chemosphere 78,

Nahrgang, J., Camus, L., Gonzalez, P., Goksøyr, A., Christiansen, J.S., Hop, H., 2009. PAH biomarker responses in polar cod (Boreogadus saida) exposed to benzo(a)pyrene. Aquat. Toxicol. 94, 309-319.

Neff, J.M. (Ed.), 1979. Polycyclic Aromatic Hydrocarbons in the Aquatic Environment: Sources, Fates and Biological Effects. Applied Science Publishers Ltd., Essex, England.

Oliveira, M., Pacheco, M., Santos, M.A., 2008. Organ specific antioxidant responses in golden grey mullet (Liza aurata) following a short-term exposure to phenanthrene. Sci. Total

Paglia, D.E., Valentine, W.N., 1967. Studies on the quantitative and qualitative characterization of erythrocyte glutathione peroxidase. J. Lab. Clin. Med. 70, 158-169. 
805 Pan, L., Ren, J., Liu, J., 2005. Effects of benzo(k)fluoranthene exposure on the biomarkers of 806 scallop Chlamys farreri. Comparative Biochemistry and Physiology Part C: Toxicology \& 807 Pharmacology 141, 248-256.

808

809 Paoletti, F., Aldinucci, D., Mocali, A., Caparrini, A., 1986. A sensitive spectrophotometric 810 method for the determination of superoxide dismutase activity in tissue extracts. Anal 811 Biochem. 154, 536-541.

812

813 Perkins, R.A., Rhoton, S., Behr-Andres, C., 2005. Comparative marine toxicity testing: A 814 cold-water species and standard warm-water test species exposed to crude oil and dispersant. 815 Cold Regions Sc.Technol. 42, 226-236.

816

817 Ramachandran, S.D., Hodson, P.V., Khan, C.W., Lee, K., 2004. Oil dispersant increases PAH 818 uptake by fish exposed to crude oil. Ecotoxicol. Environ. Saf. 59, 300-308.

819

820 Ringwood, A.H., Conners, D.E., 2000. The effects of glutathione depletion on reproductive 821 success in oysters, Crassostrea virginica. Mar. Environ. Res. 50, 207-211.

823 Roy, G., Vuillemin, R., Guyomarch, J., 2005. On-site determination of polynuclear aromatic 824 hydrocarbons in seawater by stir bar sorptive extraction (SBSE) and thermal desorption GC825 MS. Talanta 66, 540-546. 
827 Salar Amoli, H., Porgamb, A., Bashiri Sadr, Z., Mohanazadeh, F., 2006. Analysis of metal 828 ions in crude oil by reversed-phase high performance liquid chromatography using short 829 column. J. Chromato. 1118, 82-84.

830

831 Sanchez, W., Porcher, J.-M., 2009. Fish biomarkers for environmental monitoring within the 832 Water Framework Directive of the European Union. TrAC, Trends Anal. Chem. 28, 150-158. 833

834 Schroeder, W.H., Lane, D.A., 1988. The fate of toxic airborne pollutants. Environ. Sci 835 Technol. 22, 240-246

836

837 Schwarzenbach, R.P., Gschwend, P.M., Imboden, D.M. (Eds.), 2003. Environmental Organic 838 Chemistry (second ed.). Wiley InterScience, Hoboken, USA.

839

840 Seeley, K.R., Weeks-Perkins, B.A., 1997. Suppression of natural cytotoxic cell and 841 macrophage phagocytic function in oyster toadfish exposed to 7,12842 dimethylbenz[a]anthracene. Fish Shellfish Immunol. 7, 115-121.

843

844 Sies, H., 1999. Glutathione and its role in cellular functions. Free Radical Biol. Med. 27, 916845921.

846

847 Stegeman, J.J., 1987. Cytochrome P450 isozymes and monoxygenase activity in aquatic 848 animals. Environ. Health Perspect. 71, 87-95. 
850 Sun, Y., Yu, H., Zhang, J., Yin, Y., Shi H., Wang, X., 2006. Bioaccumulation, depuration and 851 oxidative stress in fish (Carassius auratus) under phenanthrene exposure. Chemosphere 63, $1319-1327$

853

854 Tiehm, A., 1994. Degradation of polycyclic aromatic hydrocarbons in the presence of 855 synthetic surfactants. Appl. Environ. Microbiol. 60, 258-263.

856

857 Van der Oost, R., Beyer, J., Vermeulen, N.P.E., 2003. Fish bioaccumulation and biomarkers 858 in environmental risk assessment: a review. Environ. Toxicol. Pharmacol. 13, 57-149.

859

860 Vandeputte, C., Guizon, I., Genestie-Denis, I., Vannier, B., Lorenzon, G., 1994. A microtiter 861 plate assay for total glutathione and glutathione disulfide contents in cultured/isolated cells: 862 performance study of a new miniaturized protocol. Cell Biol. Toxicol. 10, 415-421.

863

864 Wang, L., Yan, B., Liu, N., Li, Y., Wang, Q., 2008. Effects of cadmium on glutathione 865 synthesis in hepatopancreas of freshwater crab, Sinopotamon yangtsekiense. Chemosphere 74, $866 \quad 51-56$

867

868 Xue, W., Warshawsky, D., 2005. Metabolic activation of polycyclic and heterocyclic 869 aromatic hydrocarbons and DNA damage: A review. Toxicol. Appl. Pharmacol. 206, 73-93. 870

871 Yano, T., 1992. Assays of hemolytic complement activity. in: Stolen, J.S., Fletcher, T.C., 872 Anderson, D.P., Kaattari, S.L., Rowley, A.F. (Eds.). Techniques in Fish Immunology. SOS 873 Publications, Pair Haven, New Jersey, USA, pp. 131-142. 
Yin, Y., Jia, H., Sun, Y., Yu, H., Wang, X., Wu, J., Xue, Y., 2007. Bioaccumulation and ROS generation in liver of Carassius auratus, exposed to phenanthrene. Comparative Biochemistry and Physiology Part C: Toxicology \& Pharmacology 145, 288-293.

878

891

\begin{tabular}{|l|l|l|l|l|l|}
\hline & $\begin{array}{l}{[\mathrm{TPHs}]_{\mathrm{T}=0 \mathrm{~h}}} \\
(\mathrm{mg} / \mathrm{L})\end{array}$ & $\begin{array}{l}{[\mathrm{TPHs}]_{\mathrm{T}=48 \mathrm{~h}}} \\
(\mathrm{mg} / \mathrm{L})\end{array}$ & $\begin{array}{l}{[\Sigma \mathrm{PAHs}]_{\mathrm{T}=0 \mathrm{~h}}} \\
(\mu \mathrm{g} / \mathrm{L})\end{array}$ & $\begin{array}{l}{[\Sigma \mathrm{PAHs}]_{\mathrm{T}=48 \mathrm{~h}}} \\
(\mu \mathrm{g} / \mathrm{L})\end{array}$ & $\begin{array}{l}{[\text { Dispersant }]_{\mathrm{nom} .}} \\
(\mathrm{mg} / \mathrm{L})\end{array}$ \\
\hline $\mathrm{C}$ & n.d. & n.d. & n.d. & n.d. & n.a. \\
\hline CD & $39.1 \pm 4.1$ & $25.1 \pm 3.1$ & $43.98 \pm 5.5$ & $26.34 \pm 2.7$ & 3.33 \\
\hline MD & $13.15 \pm 2.6$ & $9.30 \pm 0.2$ & $39.09 \pm 0.6$ & $20.63 \pm 0.1$ & n.a. \\
\hline WSF & n.d. & n.d. & $5.16 \pm 0.6$ & $0.47 \pm 0.07$ & n.a. \\
\hline D & n.d. & n.d. & n.d. & n.d. & 3.33 \\
\hline
\end{tabular}

Zhang, J.F., Wang, X.R., Guo, H.Y., Wu, J.C., Xue, Y.Q., 2004. Effects of water-soluble fractions of diesel oil on the antioxidant defenses of the goldfish, Carassius auratus Ecotoxicol. Environ. Saf. 58, 110-116.

Table 1: Dispersant nominal concentration, TPHs and sum of 16 parents and alkylated USEPA PAHs ( $\mathrm{PAH})$ concentration in the five exposure media at the beginning $(\mathrm{T}=0 \mathrm{~h})$ and at the end of the exposure ( $\mathrm{T}=48 \mathrm{~h}$ ) to $\mathrm{C}$ (Control), $\mathrm{CD}$ (Chemically Dispersed oil), MD (Mechanically Dispersed oil), WSF (Water Soluble Fraction of oil) and D (Dispersant). Values are expressed as mean \pm standard error mean of both experimental replicates. n.d. $=$ not detected. n.a. $=$ not assessed. 
894 Table 2: Concentration of 16 US-EPA PAHs (alkylated and parents) in sea water during CD

895 (Chemically Dispersed oil), MD (Mechanically Dispersed oil) and WSF (Water Soluble

896 Fraction of oil) exposures. Values are expressed as mean \pm standard error mean of both

897 experimental replicates. n.d. $=$ not detected.

898

899

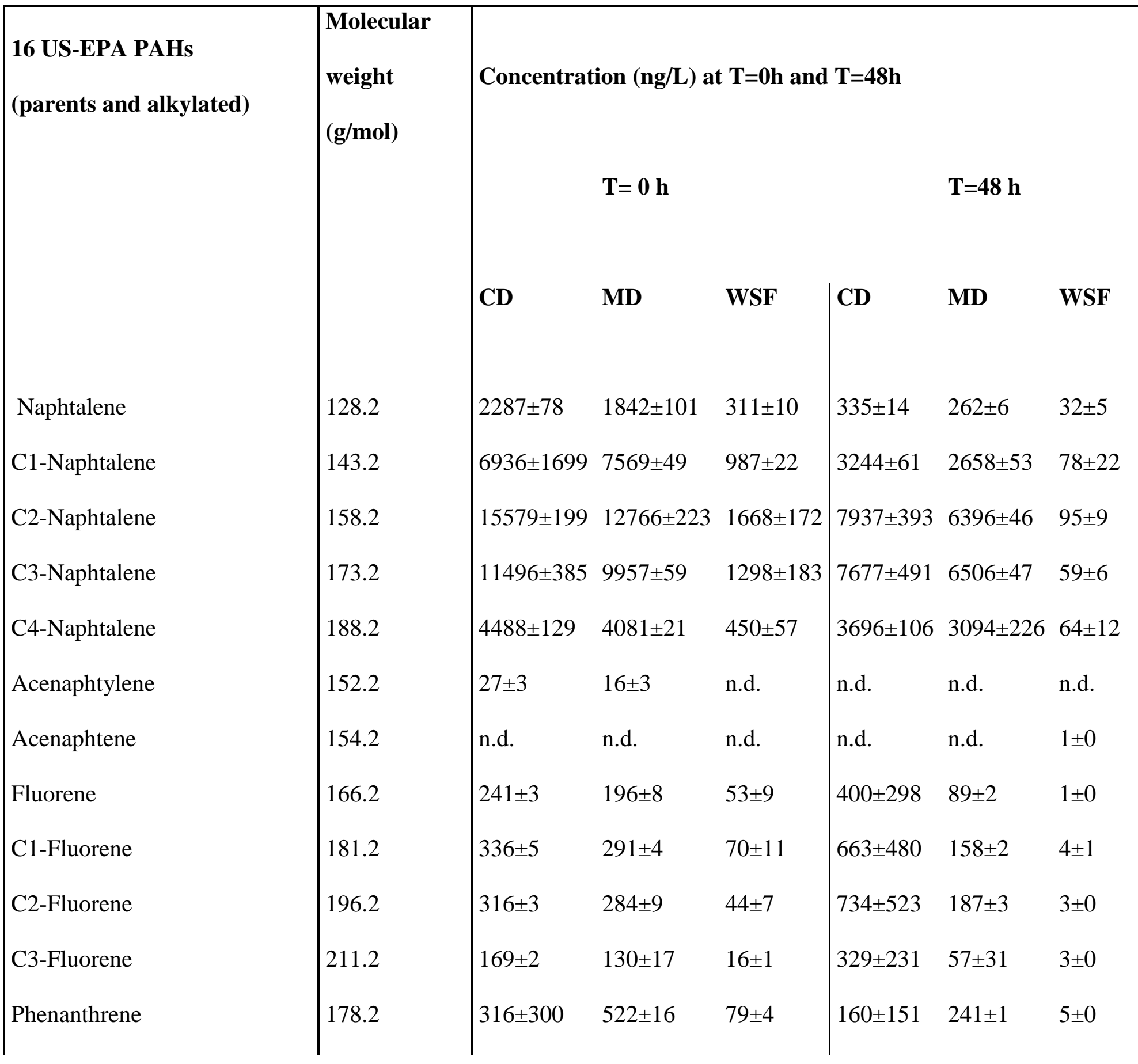




\begin{tabular}{|c|c|c|c|c|c|c|c|}
\hline Anthracene & 178.2 & $3 \pm 0$ & $8 \pm 8$ & $2 \pm 1$ & n.d. & $6 \pm 6$ & n.d. \\
\hline C1-Phenanthrenes/Anthracene & 193.2 & $959 \pm 32$ & $818 \pm 17$ & $66 \pm 23$ & $569 \pm 18$ & $467 \pm 3$ & $5 \pm 0$ \\
\hline C2-Phenanthrenes/Anthracene & 208.2 & $489 \pm 4$ & $390 \pm 25$ & $34 \pm 4$ & $326 \pm 2$ & $295 \pm 9$ & n.d. \\
\hline C3-Phenanthrenes/Anthracene & 223.2 & $136 \pm 1$ & $89 \pm 0$ & $8 \pm 1$ & $75 \pm 0$ & $68 \pm 2$ & n.d. \\
\hline C4-Phenanthrenes/Anthracene & 238.2 & $36 \pm 5$ & $29 \pm 4$ & n.d. & $23 \pm 1$ & $17 \pm 3$ & n.d. \\
\hline Fluoranthene & 202.3 & n.d. & $2 \pm 2$ & $1 \pm 0$ & $2 \pm 0$ & $1 \pm 1$ & n.d. \\
\hline Pyrene & 202.3 & n.d. & n.d. & n.d. & n.d. & n.d. & n.d. \\
\hline C1-Fluoranthenes/Pyrenes & 217.3 & n.d. & n.d. & n.d. & n.d. & $3 \pm 3$ & n.d. \\
\hline C2-Fluoranthenes/Pyrenes & 232.3 & n.d. & $7 \pm 7$ & n.d. & $9 \pm 1$ & $5 \pm 5$ & n.d. \\
\hline C3-Fluoranthenes/Pyrenes & 247.3 & n.d. & $4 \pm 4$ & n.d. & $3 \pm 3$ & $3 \pm 3$ & n.d. \\
\hline Benzo $[a]$ anthracene & 228.3 & n.d. & n.d. & n.d. & $1 \pm 0$ & n.d. & n.d. \\
\hline Chrysene & 228.3 & $8 \pm 8$ & $9 \pm 9$ & $6 \pm 3$ & $27 \pm 8$ & $19 \pm 5$ & $14 \pm 2$ \\
\hline $\operatorname{Benzo}[b+k]$ fluoranthene & 252.3 & $3 \pm 1$ & $6 \pm 0$ & $5 \pm 0$ & $10 \pm 6$ & $8 \pm 3$ & $9 \pm 1$ \\
\hline Benzo $[a]$ pyrene & 252.3 & $3 \pm 0$ & $3 \pm 0$ & $2 \pm 0$ & $5 \pm 1$ & $5 \pm 0$ & $4 \pm 1$ \\
\hline Benzo $[g, h, i]$ perylene & 276.3 & $34 \pm 5$ & $3 \pm 3$ & $32 \pm 3$ & $4 \pm 1$ & $3 \pm 1$ & $4 \pm 4$ \\
\hline Indeno $[1,2,3-c d]$ pyrene & 276.3 & $51 \pm 31$ & $31 \pm 0$ & $3 \pm 0$ & $49 \pm 0$ & $37 \pm 0$ & $40 \pm 0$ \\
\hline Dibenzo $[a, h]$ anthracene & 278.4 & $63 \pm 3$ & $39 \pm 3$ & $25 \pm 1$ & $57 \pm 4$ & $45 \pm 2$ & $48 \pm 4$ \\
\hline
\end{tabular}

900

901

902

903

904

905

906 
907

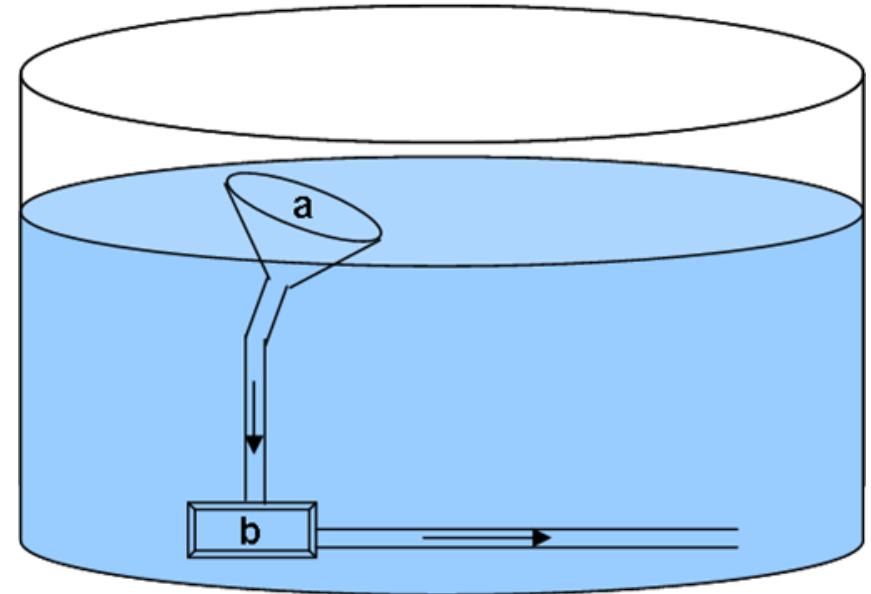

908 Figure 1: The experimental system constituted of a funnel (a) linked to a water pump (b) in a 909 300-1 sea tank. $(\rightarrow)$ indicates the direction of seawater and/or contaminants through the experimental system

a)

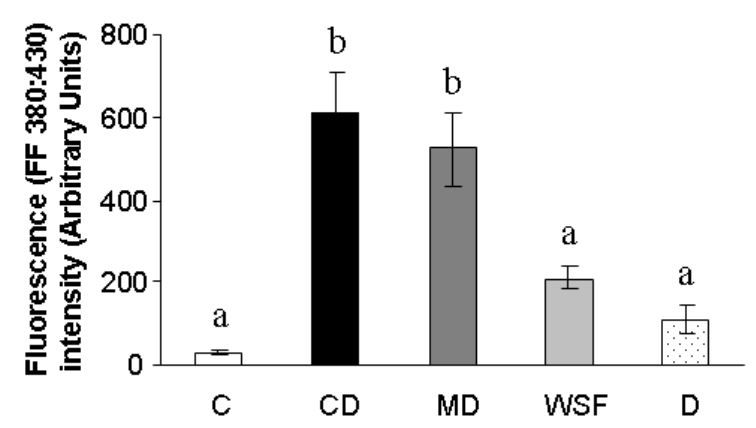

b)

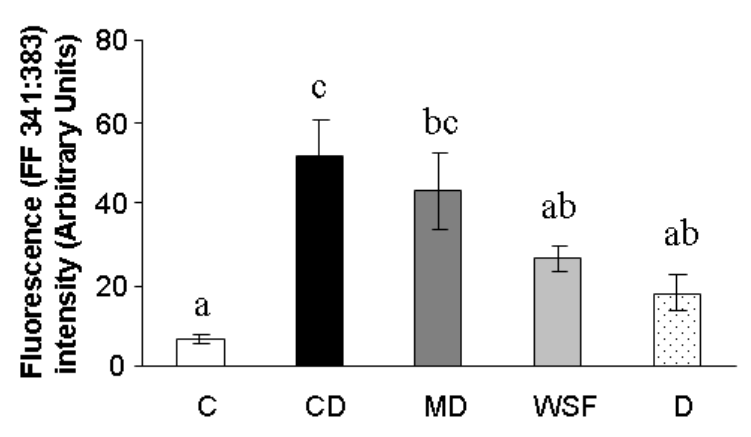

913

914 Figure 2: Fixed wavelength fluorescence (FF) of bile reflecting biliary PAHs metabolites

915 levels after 48 h exposure to Control solution (C), Chemically Dispersed oil solution (CD),

916 Mechanically Dispersed oil solution (MD), Water Soluble Fraction solution (WSF) and

917 Dispersant solution (D): (a) FF 380:430 (benzo[a]pyrene type of metabolites); (b) FF 341:383

918 (pyrene derived type of metabolites). Levels are expressed as fluorescence intensity. Values

919 represent mean \pm standard error ( $\mathrm{n}=10$ per treatment). Different letters above bars indicate a

920 significant difference, where $\mathrm{P}<0.05$. 


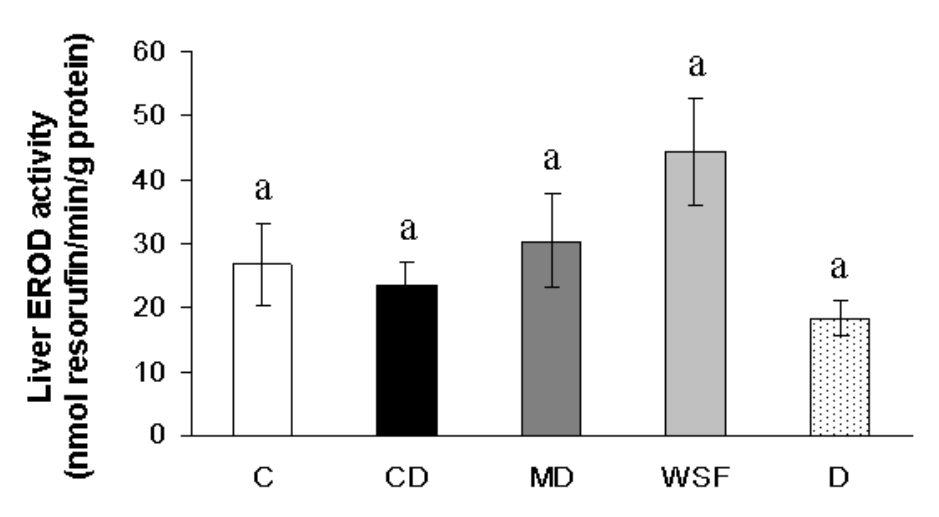

924 Figure 3: EROD (7-ethoxy-resorufin-O-deethylase) activity in Liza aurata after $48 \mathrm{~h}$

925 exposure to Control solution (C), Chemically Dispersed oil solution (CD), Mechanically

926 Dispersed oil solution (MD), Water Soluble Fraction (WSF) solution and Dispersant solution

927 (D). Values represent mean \pm standard error ( $n=10$ per treatment). Different letters above bars 928 indicate a significant difference, where $\mathrm{P}<0.05$.

929

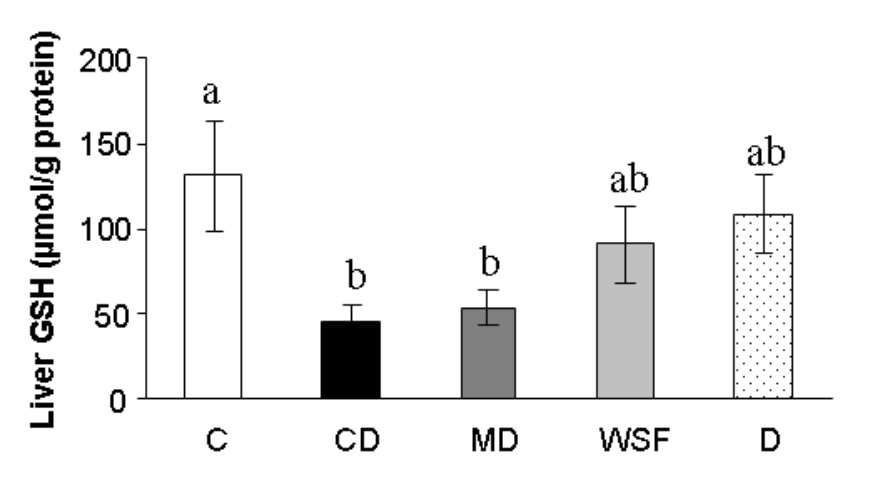

930

931 Figure 4: Total glutathione (GSH) content in liver of Liza aurata after $48 \mathrm{~h}$ exposure to

932 Control solution (C), Chemically Dispersed oil solution (CD), Mechanically Dispersed oil

933 solution (MD), Water Soluble Fraction (WSF) solution and Dispersant solution (D). Values

934 represent mean \pm standard error ( $\mathrm{n}=10$ per treatment). Different letters above bars indicate a

935 significant difference, where $\mathrm{P}<0.05$. 
a)

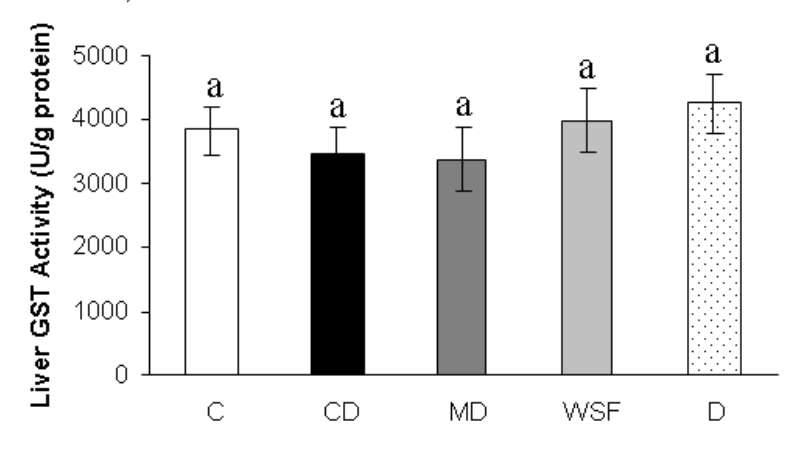

c)

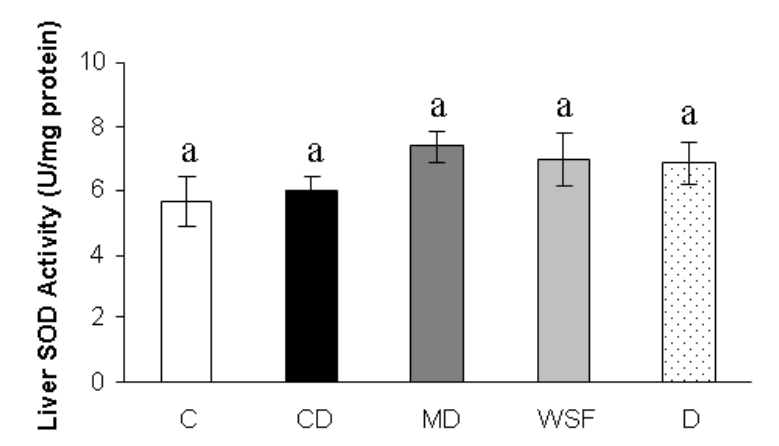

b)

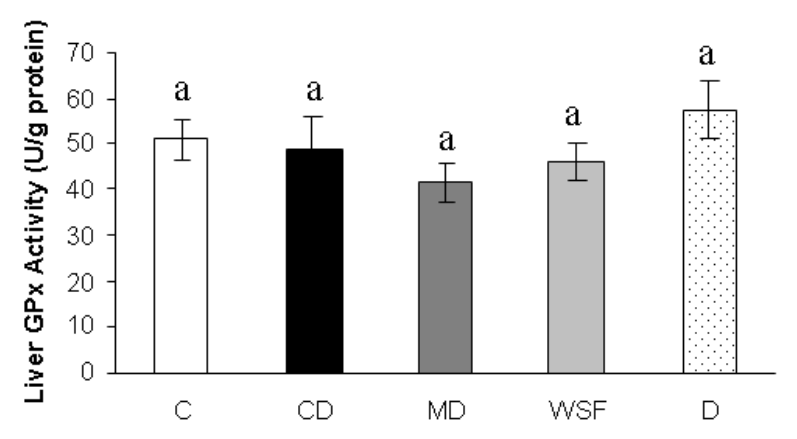

d)

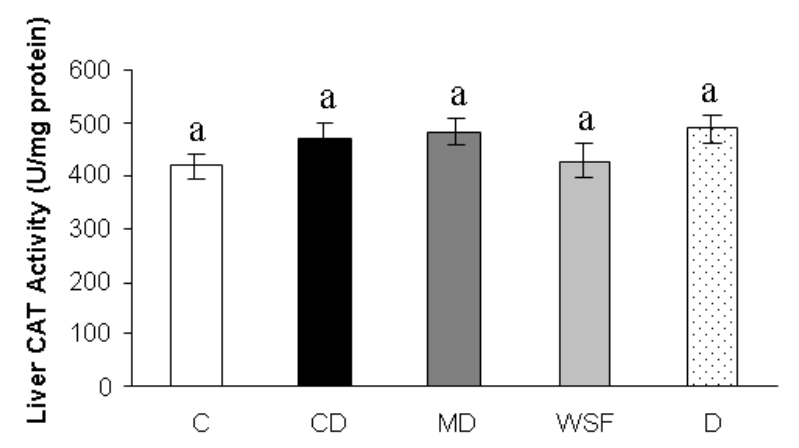

937 Figure 5: a) Glutathione S-Transferase (GST) activity, b) Glutathione Peroxidase (GPx)

938 activity, c) Superoxide Dismutase (SOD) activity and d) Catalase (CAT) activity in liver of

939 Liza aurata after $48 \mathrm{~h}$ exposure to Control solution (C), Chemically Dispersed oil solution

940 (CD), Mechanically Dispersed oil solution (MD), Water Soluble Fraction (WSF) solution and

941 Dispersant solution (D). Values represent mean \pm standard error ( $n=10$ per treatment).

942 Different letters above bars indicate a significant difference, where $\mathrm{P}<0.05$.

943

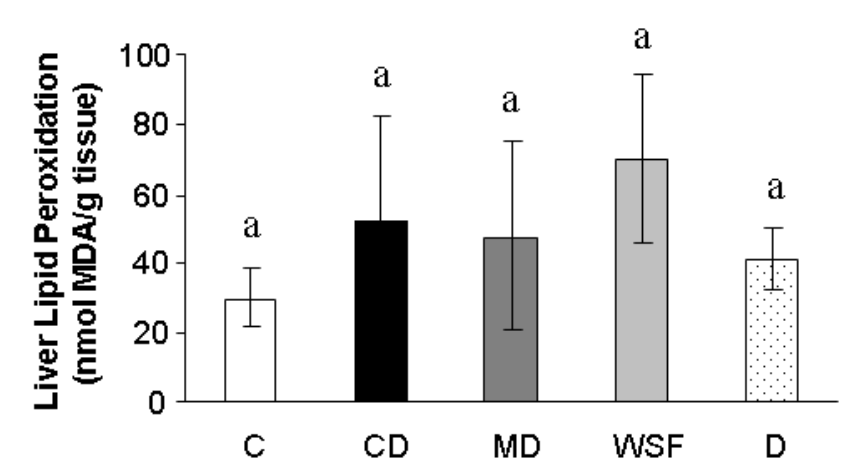


945 Figure 6: Lipid peroxidation in liver of Liza aurata after $48 \mathrm{~h}$ exposure to Control solution

946 (C), Chemically Dispersed oil solution (CD), Mechanically Dispersed oil solution (MD),

947 Water Soluble Fraction (WSF) solution and Dispersant solution (D). Values represent mean \pm

948 standard error ( $\mathrm{n}=10$ per treatment). Different letters above bars indicate a significant

949 difference, where $\mathrm{P}<0.05$.

950

951

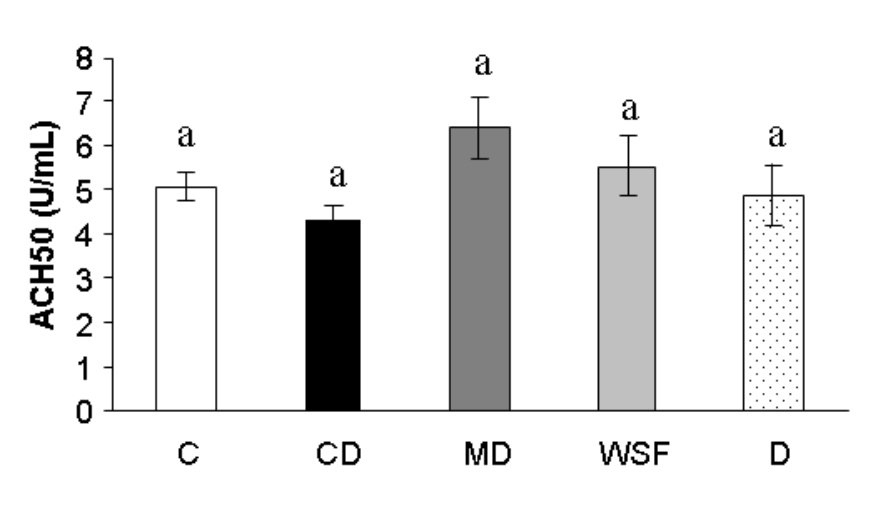

952 Figure 7: Haemolytic activity of alternative complement pathway (ACH 50) in plasma of

953 Liza aurata after $48 \mathrm{~h}$ exposure to Control solution (C), Chemically Dispersed oil solution

954 (CD), Mechanically Dispersed oil solution (MD), Water Soluble Fraction (WSF) solution and

955 Dispersant solution (D). Values represent mean \pm standard error $(n=10$ per treatment).

956 Different letters above bars indicate a significant difference, where $\mathrm{P}<0.05$.

957

958 